OPEN ACCESS

Edited by:

Alex Chaparro,

Embry-Riddle Aeronautical University,

United States

Reviewed by:

Mauro Mediavilla,

University of Valencia, Spain

Ai Liu,

Hiroshima University, Japan

*Correspondence:

Anna Schlomann

schlomann@nar.uni-heidelberg.de

Specialty section:

This article was submitted to

Human-Media Interaction,

a section of the journal

Frontiers in Computer Science

Received: 28 October 2021

Accepted: 14 December 2021

Published: 10 January 2022

Citation:

Schlomann A, Even $C$ and Hammann $T$ (2022) How Older Adults

Learn ICT-Guided and Self-Regulated Learning in Individuals

With and Without Disabilities.

Front. Comput. Sci. 3:803740.

doi: 10.3389/fcomp.2021.803740

\section{How Older Adults Learn ICT-Guided and Self-Regulated Learning in Individuals With and Without Disabilities}

\author{
Anna Schlomann ${ }^{1,2 *}$, Christiane Even ${ }^{1}$ and Torsten Hammann ${ }^{2}$ \\ ${ }^{1}$ Network Aging Research, Heidelberg University, Heidelberg, Germany, ${ }^{2}$ Institute for Educational Sciences, Heidelberg \\ University of Education, Heidelberg, Germany
}

Learning to use information and communication technologies (ICT) may be more difficult for older people due to decreases in fluid intelligence, generational effects, and other age-related effects. Especially older people with intellectual disabilities (ID) are at a high risk of digital exclusion. To enable all older adults to use ICT, individualized technology training may be provided. However, little is known about the ICT learning preferences among older people with ID. Based on semi-structured interviews with older adults ( $n=7$, mean age $=76.6$ years $)$ and older adults with ID $(n=14$, mean age $=62.4$ years), this paper analyzes learning strategies, preferences, and learning settings. The results from content analysis show that guided learning with personal explanations in a one-to-one setting is the most preferred learning format in both groups of older adults. While many older adults without ID additionally favor self-regulated learning (i.e., learning with manuals or videos), older adults with ID mostly rely on guided learning with personal assistance. The differences can be explained by different abilities (e.g., reading skills) and social networks (e.g., living situation, having children). Not all older adults have a family or an institutional support network to help them learn ICT and community organizations may provide additional support. Researchers and practitioners should be aware of the diverse knowledge backgrounds and competencies in the group of older adults. ICT training in old age should be ideally composed in a modular way embedding self-regulated learning formats into guided learning modules.

Keywords: aging, old age, intellectual disabilities, technology, learning preferences, digital literacy, qualitative research

\section{INTRODUCTION}

In modern, technology-driven societies, individuals of all ages need to acquire skills to operate new digital systems and products such as information and communication technologies (ICT) constantly. ICT can provide benefits for older adults such as enabling contact to close others, searching for information on the Internet, and enhance leisure time experiences (e.g., Antonucci et al., 2017; Czaja et al., 2018). However, the process of learning something new differs between younger and older people. This can be attributed to decreases in fluid intelligence with advancing age (Horn and Cattell, 1967). Fluid intelligence is associated with problem solving and comprehension processes and describes the ability to solve novel problems that are independent 
of prior learning or experiences (e.g., Cattell, 1963; Horn and Cattell, 1966). ICT learning relies on skills associated with fluid intelligence and may therefore differ between younger and older people. Older adults still lag behind in technology access and skills (Pew Research Center, 2021), a phenomenon that has been described as the age-related digital divide or "gray divide" (QuanHaase et al., 2018), and research has shown that older adults face user experience challenges in the interaction with ICT (e.g., Leung et al., 2012; Barnard et al., 2013).

There are multiple reasons for age-related differences in ICT literacy and ICT learning: First, there may be relevant generational effects. Older adults did not grow up with digital technology, meaning that they belong to a different technology generation than younger people (Sackmann and Winkler, 2013). While important technological skills are developed in early phases of life, older people need to catch up on learning these skills in later phases of life, when learning something new is more difficult (see above). Second, additional age effects beyond changes in fluid intelligence may account for the differences between young and old. In old age, individuals may face challenges in sensory and motor functions, which can negatively influence the learning process and user experience of ICT (e.g., Barnard et al., 2013). Third, older people vary in their physical and cognitive abilities. Among other things, people with cognitive impairments and intellectual disabilities (ID) need more support in their learning process. They benefit to a greater extent from pre-structured learning settings in multimodal form (e.g., spoken explanation supported by pictures), repeated practicing combined with a specific activity, and personal support (Podlesch, 2018). Given this heterogeneity in old age in general, there are also differences in the digital skills within the group of older adults (Quan-Haase et al., 2018). Especially older adults with cognitive impairments and ID may face challenges in ICT learning (Schmidt and Wahl, 2019; Smith et al., 2020) and older people with ID are among the groups with the highest risk of digital exclusion (Ehlers et al., 2020). While this group has received little attention in research on the digital divide so far (Balasuriya et al., 2018), ICT may have great potential for older people with ID in terms of supporting everyday life (relatively) independent living, and maintaining autonomy and social participation.

To reduce these age-related inequalities in ICT use and to increase ICT literacy among all older adults, individualized technology training may be provided (see e.g., Hickman et al., 2007; Mitzner et al., 2008). A relevant distinction of learning formats is between self-regulated learning (Boekaerts, 1997) and guided learning (Mayer and Alexander, 2011; Fritz et al., 2018).

Self-regulated learning describes different forms of learning in which individuals plan, monitor, and evaluate their own learning processes (Zimmerman and Schunk, 1989; Boekaerts, 1997). This form of learning is free of externally determined learning goals and content. Common forms are learning with manuals and other written or audio-visual materials, and "trial and error" strategies. Research has shown that many older adults prefer forms of self-regulated learning when learning ICT (Mitzner et al., 2008) and often learn from reading manuals (Tsai et al., 2012; Barnard et al., 2013). The main purposes of using manuals from the perspective of older adults are to obtain product knowledge and to recall forgotten information (Tsai et al., 2012). However, most manuals are designed for younger target groups (Christoffersen and Møller, 2010). Small font sizes, technical terms that are not explained, poor translations, and incomprehensible wording may cause learning problems for older people (Schwender, 2009; Tsai et al., 2012).

Guided learning comprises educational programs, training courses, and one-to-one explanations (Mayer and Alexander, 2011). In the context of technology learning, research has shown that guided learning formats in a one-to-one setting are among the preferred learning formats of older adults (Barnard et al., 2013). In training courses, instructors often have to deal with different levels of abilities among the older participants which makes it necessary to develop specific teaching strategies such as unscripted learning and the inclusion of assistance by peers (Chiu et al., 2019). Barlott et al. (2020) state that people with ID especially need some kind of training, often in the form of personal guidance, due to their deficits in personal competencies like language ability, memory and executive functions or literacy skills, but also due to the complexity of the technology.

However, the evidence about the "best" learning format is mixed and little is known about the acquisition and specific learning strategies and preferences among older adults with ID when learning ICT. Against this background, the aim of this brief research report is to explore the learning strategies and preferences among older adults with and without ID. A distinctive feature of our study is that we analyze the data with reference to the two broad concepts of guided learning and self-regulated learning. Based on the results, we derive practical implications and recommendations for ICT training in old age.

\section{METHODS}

The study was approved by the local university's ethics committee (EV2020/04-02). All participants and in some cases also their legal representative gave informed consent. We conducted qualitative research to analyze the learning strategies and preferences of older adults in the context of ICT learning. Qualitative research allows to study subjective experiences and meaning from the perspective of the individual (Flick, 2009). Data collection was realized in semi-structured interviews and the discussion of learning strategies and preferences was embedded into a larger context. Topics discussed were: general life context and everyday life routines, interest in technology use, learning strategies and preferences for new technologies, and experiences with voice-based systems.

In this paper, we focus exclusively on the topics of learning strategies and preferences. In this section of the interview, participants were first asked open questions about their learning strategies and preferences when learning new ICT. When participants did not report on their own, there were follow-up questions about their opinions to personal guidance, manuals, and videos to gain insights into different preferences in the context of guided and self-regulated learning. For participants with ID, an interview guideline in easy language (Maaß, 2020) 
TABLE 1 | Sample characteristics.

\begin{tabular}{lcc}
\hline & \multicolumn{2}{c}{ Group } \\
\cline { 2 - 3 } & OA & ID \\
\hline$n$ & 7 & 14 \\
M age (SD) & $76.6(7.91)$ & $62.4(9.08)$ \\
Age range & $65-85$ & $51-84$ \\
Sex & & \\
$\quad$ \% female & 57.1 & 21.4 \\
$\quad$ \% male & 42.9 & 78.6 \\
ICT experience: \% active users & 100 & 50 \\
M persons in household (SD) & $0.71(0.49)$ & $3.64(3.15)$ \\
Family status & & 28.6 \\
$\quad$ \% married or in a relationship & 85.7 & 71.4 \\
$\quad \%$ single & 14.3 & $0.1(0.90)$ \\
M children (SD) & $2.6(0.54)$ & \\
\hline
\end{tabular}

M, Mean; SD, Standard deviation.

was applied. The interview guideline was adapted to the individuals and their specific knowledge and background, e.g., some questions were omitted when the participants did not know any ICT or when they were not interested in learning (new) ICT at all.

All interviews were transcribed and qualitative content analysis was applied to analyze the interviews (Hsieh and Shannon, 2005). Some analytical categories were developed in a deductive approach from previous research and the interview guideline (i.e., main categories "learning strategies and preferences" and "learning setting;" sub-categories "personal guidance," "manuals," "videos" for learning strategies and preferences and "one-to-one" for learning setting). Further categories were added in an inductive approach while one category was added as in vivo code (i.e., "learning by doing"). To illustrate the categories, direct quotes from the interviews are reported in the results section including the participant number and the respective lines in the interview transcripts.

In total, $n=21$ interviews were realized. Of those, $n=7$ were conducted with older adults without disabilities (OA) and $n=14$ were conducted with older adults with intellectual disabilities (ID). The sample description is provided in Table 1. On average, the participants with ID were younger than the older adults without ID and in the group of persons with ID, more men than women were interviewed. While all participants in the older adult group reported having ICT experience, only half of the participants with ID reported having this experience. Differences also existed in the family structures: Participants with ID lived in larger households (i.e., assisted living residence or ambulant assisted living), they were less often married or in a relationship and had less children than older adults without ID (see Table 1).

\section{RESULTS}

Six main categories were identified in the interviews: (1) Reasons for the use of new ICT or functions, (2) Reasons for the non-use
TABLE 2 | Results of the content analysis for learning strategies and preferences.

\begin{tabular}{|c|c|c|c|c|c|c|}
\hline & & \multicolumn{5}{|c|}{ Learning strategies and preferences ${ }^{a}$} \\
\hline & & $\begin{array}{l}\text { Personal } \\
\text { guidance }^{\mathrm{a}}\end{array}$ & Videos $^{a}$ & Manuals $^{\mathbf{a}}$ & $\begin{array}{l}\text { Learning } \\
\text { by doing }\end{array}$ & $\begin{array}{c}\text { Internet } \\
\text { research }\end{array}$ \\
\hline \multirow[t]{2}{*}{$\mathrm{OA}$} & Codings $(n)$ & 30 & 13 & 7 & 10 & 8 \\
\hline & Participants $(n)^{\mathrm{c}}$ & 6 of 7 & 6 of 7 & 5 of 7 & 6 of 7 & 3 of 7 \\
\hline \multirow[t]{2}{*}{ ID } & Codings ( $n)$ & 25 & 10 & 4 & 18 & 1 \\
\hline & Participants $(n)^{c}$ & 11 of 14 & 6 of 14 & 4 of 14 & 8 of 14 & 1 of 14 \\
\hline
\end{tabular}

${ }^{a}$ Category developed in a deductive approach, ${ }^{b}$ Category developed in an inductive approach. ${ }^{\circ}$ The interviews with older adults were significantly longer, which resulted in more codings as well. In order to exclude these duplications and to aim for a better comparison between the two groups, the table also shows how many participants mentioned each category at least once.

TABLE 3 | Results of the content analysis for learning setting.

\begin{tabular}{|c|c|c|c|c|}
\hline & & \multicolumn{3}{|c|}{ Learning setting ${ }^{a}$} \\
\hline & & One-to-one ${ }^{a}$ & Individual $^{\mathbf{b}}$ & Group $^{b}$ \\
\hline \multirow[t]{2}{*}{$\mathrm{OA}$} & Codings (n) & 25 & 10 & 1 \\
\hline & Participants $(n)^{c}$ & 6 of 7 & 5 of 7 & 1 of 7 \\
\hline \multirow[t]{2}{*}{ ID } & Codings (n) & 19 & 6 & 6 \\
\hline & Participants $(n)^{C}$ & 10 of 14 & 2 of 14 & 4 of 14 \\
\hline
\end{tabular}

${ }^{a}$ Category developed in a deductive approach, ${ }^{b}$ Category developed in an inductive approach. ${ }^{C}$ The interviews with older adults were significantly longer, which resulted in more codings as well. In order to exclude these duplications and to aim for a better comparison between the two groups, the table also shows how many participants mentioned each category at least once.

of new ICT or functions, (3) Alternative forms of interaction without ICT, (4) Learning strategies and preferences, (5) Learning settings, (6) Leisure activities and everyday life routines. In this brief research report, we focus only on the main categories (4) and (5) that are associated with the ICT learning process (see Tables 2, 3).

\section{Learning Strategies and Preferences}

Participants reported of different learning strategies and preferences, including learning with personal guidance, learning with videos, learning with manuals, learning by doing, and learning via Internet research. Heterogeneous strategies and preferences were identified (see Table 2).

Both groups most frequently named personal guidance as means of choice (6 of 7 OA, 11 of 14 ID). For example, OA02 "would always prefer the personal [explanation], I would always ask [my son]" (OA02, 1. 112). However, this was the only category preferred by older adults with ID almost as often as by older adults. Regarding learning with videos, most older adults (6 of 7) thought that this could be a good opportunity, if the video is "slow and really getting to the point [...], not rambling [...] not [...] too colorful [...], simple (OA02, l. 152-158). Learning with videos was unknown to almost all of the participants with ID, nevertheless six older adults with ID could imagine using them in the future. 
Manuals were also part of the learning preferences and strategies of most older adults (5 of 7). However, two older adults rejected manuals because of their complexity and technical terms, as they "contain a lot of words that I don't understand at all" (OA05, 1. 137). Therefore, the cited person preferred the option of being able to ask questions directly. In contrast, only one third of the older adults with ID preferred written instructions (4 of 14), which was also justified with their own reading skills: "I can also look at pictures or something like that, but there has to be a caregiver anyway who reads it to me" (ID08, 1. 39).

Conducting Internet research was the most unpopular learning preference or strategy in both groups, whereas older adults preferred this more often ( 3 of 7 ) compared to people with ID (1 of 14). In particular, there was often a combination with the category "learning by doing." For example, OA7 stated that she uses "learning by doing [...] and then googling if I want to know something" (1. 94). The strategy of learning by doing was mentioned quite often in both groups (6 of 7 OA, 8 of 14 ID) and it was the second most frequently mentioned preference by people with ID.

In summary, most participants among the older adults reported a multi-media learning format and applied or preferred several kinds of learning strategies, e.g., "It's often learning by doing. But of course, I also watch [videos] on YouTube, or you can read a lot. If you don't get any further, you can ask Google. And that's how you always find your way" (OA06, 1. 52). On average, older adults combined four of the five learning strategies and preferences. The picture was different for people with ID. They reported less on combined learning formats and on average, two of the five strategies or preferences were named. Personal guidance was mostly preferred in the group of people with ID, followed by learning by doing.

\section{Learning Setting}

The most preferred learning setting among all interviewees was learning in one-to-one settings, which is related to personal guidance as the most popular learning strategy and preference. Older adults always referred to situations, in which (younger) family members (e.g., children or grandchildren) showed and explained the usage of new ICT: "In particular, our generation [...] always needs the introduction by the young people. That is, [...] not in seminars, but in the family. [...] My daughter then came and explained it to us and everyone has different requirements again" (OA04, 1. 188). In contrast, older adults with ID mentioned only institutional workers (e.g., professional caregivers or assistants) who showed, explained and repaired their (new) ICT: "The one staff member set it up and showed how it worked" (ID13, 1. 308).

While group settings, such as computer learning courses, were named rather rarely in both groups (1 of 7 OA, 4 of 14 ID), there were clear differences in opinions about the setting of individual learning between the two groups. On the one hand, most older adults were familiar with individual learning (5 of 7): "Sometimes, I also watch the tips and tricks, for example on the
iPhone you always get that. And I also look at that and then I can already do many things" (OA07, l. 112). On the other hand, the individual learning setting was the exception among people with ID and only two participants reported this strategy. The report by ID02 shows that learning and using ICT on its own might also have negative consequences. This person used the Internet on his own, but refused it afterwards, saying it was too "dangerous" (l. 33) for him.

To sum up, both groups preferred the one-to-one setting, whereas older adults additionally used or would like to use an individual learning approach.

\section{DISCUSSION}

This qualitative study focused on ICT learning strategies, preferences, and learning setting among older adults with and without disabilities. The results fit well with previous research about a digital divide within the older generation (Quan-Haase et al., 2018) and provide new insights into the context of ICT learning in old age. The reasons for learning and using new ICT may be very diverse and older people mainly start to use new devices or functions driven by real-life needs and interests (Sayago et al., 2013). The main contribution of this research is the analysis of guided and self-regulated ICT learning strategies, preferences, and settings in a heterogeneous sample of older adults, including older people with ID. Although there are some similarities between the two groups (OA and ID), there are also clear differences.

The results indicate that guided learning is particularly preferred and personal explanations in a one-to-one setting are of very high relevance. This applies for both groups of older adults and contrasts clearly to the study results by Leung et al. (2012) who reported that older adults prefer learning alone to learning with others (e.g., with family members). However, our results are in line with the results of the study by Barnard et al. (2013) in which guided step-by-step instructions are identified as one learning strategy or preference for older adults who usually organize that kind of support within their family. Concerning the recruitment of (informal) tutors or teaching persons, our study clearly reflects the different social networks of the participants with and without ID. Older adults without ID find support in ICT learning within their family and are mostly assisted by children or grandchildren. For older people with ID, institutional staff members (i.e., professional caregivers and assistants) take over the role of explaining and teaching the use of ICT. People with ID have a smaller number of people in their personal networks who can provide assistance (Barlott et al., 2020). Furthermore, our sample description shows that they rarely have own children and hence younger and tech-savvy relatives who can support them in learning to use ICT.

The findings for self-regulated learning differ to a larger extent between the two groups. Many older adults without ID combined guided learning with self-regulated learning strategies such as using manuals, videos, and learning by doing. In contrast, older adults with ID clearly preferred the guided learning format. Learning with manuals was mentioned as one relevant learning 
strategy among older adults in previous studies (Leung et al., 2012; Tsai et al., 2012) and seems to be a nearby learning opportunity because most ICT come with off the shelf manuals. However, in our study, learning with manuals was not the preferred learning strategy or preference in the group of older adults and was even clearly rejected by two older adults due to the technical language. These problems have also been reported in previous work (Schwender, 2009; Tsai et al., 2012). In the group of older adults with ID, learning with manuals was never mentioned in the self-reports. When they were explicitly asked about this learning strategy, only four of 14 interviewees mentioned manuals as learning preference as some interviewees with ID could not read well.

\section{Practical Implications}

The most preferred forms of learning in both groups were guided learning formats especially in one-to-one settings. Depending on their personal situations, the participants reported to get support from (younger) relatives or institutional staff members. However, it must be considered that not all older adults have a family or an institutional support network to help them learn ICT. It is therefore important that organizations in the community, e.g., adult education centers, community centers or senior universities, create ICT learning opportunities for older adults. ICT training may also be implemented in the curricula of caregivers and assistants for people with ID who are in need of even more personal guidance. Gerontological expertise about older adults' general learning preferences should be considered. For example, the learning opportunities should be connected to the everyday life ecologies of older people, they should consider the habits, routines, values, and preferences of older people, and they should be accessible also for individuals with little resources. There might be further potential in peer-to-peer concepts of ICT training in which older adults with higher ICT competence, so called "senior technology experts" teach older adults with lower ICT competence (Doh et al., 2015).

Based on the results from previous research and our study, we argue that it is important to invest more in training, education, and support for those older adults who face difficulties with ICT and to consider diverse learning preferences in the conception of technology trainings. To include older adults with cognitive impairments and ID, easy-to-read language should be applied in written materials such as manuals (Maaß, 2020). To overcome the barriers of standard manuals, guidelines have been developed to create "senior-friendly" product instructions (Fan and Truong, 2018). Amongst other things, these include aspects such as providing a better overview of all elements, explaining technical terms, and using consistent language. However, these recommendations have not been implemented in product manuals at large. Some older adults also develop own strategies to compensate for deficits in product manuals, i.e., by marking important sections or noting relevant information on an extra paper sheet (Tsai et al., 2012). This kind of knowledge and competences might also be shared with other older adults in peer-to-peer learning. It would then be the task of community organizations to provide a room where the interested (older) people can meet and exchange their knowledge and experiences. However, researchers, practitioners and designers must also be aware that some individuals in the group of older people with ID are not able to read and alternative forms of learning, including videos, picture-based material and forms of augmentative and alternative communication (AAC), should be implemented (Spriggs et al., 2017). The results from this study provide evidence that older people are generally open toward these forms of learning when they are linked to a personal explanation.

\section{Limitations}

This study has some limitations concerning the study design and analytical approach. The study sample was small, and participants were recruited using convenience sampling. Participants were generally interested in the topics of the interviews and they might therefore be more open toward different forms of ICT learning. Although our findings fit well with previous research, they cannot be generalized based on the small sample to older adults and older adults with ID in general and should be replicated in future studies. Additionally, no comparison can be made between the learning strategies and preferences among younger and older individuals because only older adults participated in this study.

There were further methodological challenges in conducting and analyzing the interviews with participants with ID. Concerning the interview texts that lay ground for the coding, there are major differences between the two groups of older adults. Most of the time, the open-ended questions elicited quite long replies in older adults without ID. In the group of older adults with ID, there was a general tendency toward minimal answers. Such short or even one-word answers recurrently led to the formulation of content-richer utterances by the interviewer as means of understanding checks, which then were often confirmed by the interviewees with minimal replies. This means, that older adults mainly produced the answers by themselves whereas answers by older adults with ID were partly coconstructed by interviewer and interviewee. These interactional patterns are well-known phenomena in so-called "atypical interaction" (Rapley and Antaki, 1996; Rasmussen, 2016; Wilkinson, 2019). Moreover, interviews with older adults with ID showed that the requirements of (i) accurately reconstructing past events (of learning strategies) and (ii) expressing one's opinion toward proposed learning preferences mostly seemed to be beyond participants' capabilities. We tried to take these aspects into account by analyzing how many participants mentioned each category at least once in addition to the total number of codings. Nevertheless, the methodological question arises of how else to account for these effects in the process of content analysis other than reflecting these differences in the discussion of the results.

\section{CONCLUSION}

In this paper, we analyzed ICT learning strategies, preferences and learning settings among older people with and without disabilities. The results show that the mostly preferred format 
of ICT learning in both groups is guided learning in one-toone settings. Further learning formats such as self-regulated learning with manuals and videos were perceived quite differently based on the competences and previous experiences of the participants. Older people with ID mainly did not prefer any form of self-regulated learning other than learning by doing while many older people without ID were more open toward self-guided learning. We therefore conclude that an ICT training for older adults should in any case include some form of a personal guidance. Further training elements should be added based on the different knowledge backgrounds and abilities of older adults and older users should be able to choose the most appropriate solution for them. In sum, we propose a training conception that is composed in a modular way. Self-regulated learning should ideally be embedded into guided learning and only applied if this fits well with the individual abilities and preferences.

\section{DATA AVAILABILITY STATEMENT}

The raw data supporting the conclusions of this article will be made available by the authors, without undue reservation.

\section{REFERENCES}

Antonucci, T. C., Ajrouch, K. J., and Manalel, J. A. (2017). Social relations and technology: continuity, context, and change. Innovat. Aging 1:igx029. doi: 10.1093/geroni/igx029

Balasuriya, S. S., Sitbon, L., Bayor, A. A., Hoogstrate, M., and Brereton, M. (2018). "Use of voice activated interfaces by people with intellectual disability," in Proceedings of the 30th Australian Conference on Computer-Human Interaction, eds G. Buchanan, and D. Stevenson (Melbourne, VIC: ACM), 102-112. doi: $10.1145 / 3292147.3292161$

Barlott, T., Aplin, T., Catchpole, E., Kranz, R., Le Goullon, D., Toivanen, A., et al. (2020). Connectedness and ICT: Opening the door to possibilities for people with intellectual disabilities. J. Intellect. Disabil. 24, 503-521. doi: $10.1177 / 1744629519831566$

Barnard, Y., Bradley, M. D., Hodgson, F., and Lloyd, A. D. (2013). Learning to use new technologies by older adults: perceived difficulties, experimentation behaviour and usability. Comput. Hum. Behav. 29, 1715-1724. doi: $10.1016 /$ j.chb.2013.02.006

Boekaerts, M. (1997). Self-regulated learning: a new concept embraced by researchers, policy makers, educators, teachers, and students. Learn. Instruct. 7, 161-186. doi: 10.1016/S0959-4752(96)00015-1

Cattell, R. B. (1963). Theory of fluid and crystallized intelligence: a critical experiment. J. Educ. Psychol. 54, 1-22. doi: 10.1037/h0046743

Chiu, C.-J., Tasi, W.-C., Yang, W.-L., and Guo, J.-L. (2019). How to help older adults learn new technology? Results from a multiple case research interviewing the internet technology instructors at the senior learning center. Comput. Educ. 129, 61-70. doi: 10.1016/j.compedu.2018.10.020

Christoffersen, E., and Møller, M. H. (2010). "Technical manuals for the elderly - can controlled language principles help?" in Online proceedings of the XVII European LSP Symposium 2009, eds C. Heine, and J. Engbert (Aarhus).

Czaja, S. J., Boot, W. R., Charness, N., Rogers, W. A., and Sharit, J. (2018). Improving social support for older adults through technology: findings from the PRISM randomized controlled trial. Gerontologist 58, 467-477. doi: $10.1093 /$ geront/gnw249

Doh, M., Schmidt, L. I., Herbolsheimer, F., Jokisch, M., and Wahl, H.-W. (2015). "Patterns of ICT use among "senior technology experts": the role of demographic variables, subjective beliefs and attitudes," in Lecture Notes in Computer Science. Human Aspects of IT for the Aged Population. Design for

\section{ETHICS STATEMENT}

The studies involving human participants were reviewed and approved by the Ethics Committee of Heidelberg University of Education (EV2020/04-02). The patients/participants provided their written informed consent to participate in this study.

\section{AUTHOR CONTRIBUTIONS}

All authors provided substantial contributions to this article from conception to final approval.

\section{FUNDING}

This publication was part of the AI-Aging project (AIbased voice assistance for older adults with and without intellectual disabilities), which was funded by the BadenWürttemberg Stiftung within the funding line Responsible Artificial Intelligence. The article processing charge was funded by the Baden-Württemberg Ministry of Science, Research, and Culture and the Heidelberg University of Education in the funding programme Open Access Publishing.

Aging, Vol. 9193, eds J. Zhou, and G. Salvendy (Los Angeles, CA: Springer International Publishing), 177-188. doi: 10.1007/978-3-319-20892-3_18

Ehlers, A., Heß, M., Frewer-Graumann, S., Olbermann, E., and Stiemke, P. (2020). "Digitale teilhabe und (digitale) exklusion im alter: expertise zum achten altersbericht der bundesregierung," in Expertisen zum Achten Altersbericht der Bundesregierung, eds C. Hagen, C. Endter, and F. Berner (Berlin: Deutsches Zentrum für Altersfragen).

Fan, M., and Truong, K. N. (2018). Guidelines for creating senior-friendly product instructions. ACM Trans. Access. Comput. 11, 1-35. doi: 10.1145/3209882

Flick, U. (2009). An Introduction to Qualitative Research, 4th edn. Los Angeles, CA: Sage Publications.

Fritz, A., Hussy, W., and Tobinski, D. (2018). Pädagogische Psychologie (3. Auflage). utb-studi-e-book: Vol. 3373. Ernst Reinhardt Verlag; UTB GmbH. Available online at: https://elibrary.utb.de/doi/book/10.36198/9783838550190

Hickman, J. M., Rogers, W. A., and Fisk, A. D. (2007). Training older adults to use new technology. J. Gerontol. Ser. B 62B, 77-84. doi: 10.1093/geronb/62.special_issue_1.77

Horn, J. L., and Cattell, R. B. (1966). Refinement and test of the theory of fluid and crystallized general intelligences. J. Educ. Psychol. 57, 253-270. doi: $10.1037 / \mathrm{h} 0023816$

Horn, J. L., and Cattell, R. B. (1967). Age differences in fluid and crystallized intelligence. Acta Psychol. 26, 107-129. doi: 10.1016/0001-6918(67)90011-X

Hsieh, H.-F., and Shannon, S. E. (2005). Three approaches to qualitative content analysis. Qual. Health Res. 15, 1277-1288. doi: 10.1177/10497323052 76687

Leung, R., Tang, C., Haddad, S., McGrenere, J., Graf, P., and Ingriany, V. (2012). How older adults learn to use mobile devices. ACM Trans. Access. Comput. 4, 1-33. doi: 10.1145/2399193.2399195

Maaß, C. (2020). Easy Language - Plain Language - Easy Language Plus: Balancing Comprehensibility and Acceptability. Berlin: Frank \& Timme. doi: 10.26530/20.500.12657/42089

Mayer, R. E., and Alexander, P. A (Eds.). (2011). "Educational psychology handbook series," in Handbook of Research on Learning and Instruction (New York, NY: Routledge). doi: 10.4324/9780203839089

Mitzner, T. L., Fausset, C. B., Boron, J. B., Adams, A. E., Dijkstra, K., Lee, C. C., et al. (2008). Older adults' training preferences for learning to use technology. Proc. Hum. Fact. Ergon. Soc. Ann. Meet. 52, 2047-2051. doi: $10.1177 / 154193120805202603$ 
Pew Research Center (2021). Mobile Technology and Home Broadband 2021. Available online at: https://www.pewresearch.org/internet/2021/06/03/mobiletechnology-and-home-broadband-2021/

Podlesch, W. (2018). "Integrationspädagogische Lernprinzipien zum Förderschwerpunkt geistige Entwicklung," in Blick zurück Nach Vorn-WegbereiterInnen der Inklusion, ed F. J. Müller (Giessen: Psychosozial-Verlag), 419-435.

Quan-Haase, A., Williams, C., Kicevski, M., Elueze, I., and Wellman, B. (2018). Dividing the grey divide: deconstructing myths about older adults' online activities, skills, and attitudes. Am. Behav. Sci. 62, 1207-1228. doi: 10.1177/0002764218777572

Rapley, M., and Antaki, C. (1996). A conversation analysis of the "acquiescence" of people with learning disabilities. J. Commu. Appl. Soc. Psychol. 6, 207-227. doi: 10.1002/(SICI) 1099-1298(199608)6:3<207::AID-CASP370>3.0.CO;2-T

Rasmussen, G. (2016). Repeated use of request for confirmation in atypical interaction. Clin. Linguist. Phon. 30, 849-870. doi: 10.1080/02699206.2016.1209244

Sackmann, R., and Winkler, O. (2013). Technology generations revisited: the internet generation. Gerontechnology 11, 493-503. doi: 10.4017/gt.2013.11.4.002.00

Sayago, S., Forbes, P., and Blat, J. (2013). Older people becoming successful ICT learners over time: challenges and strategies through an ethnographical lens. Educ. Gerontol. 39, 527-544. doi: 10.1080/03601277.2012.703583

Schmidt, L. I., and Wahl, H.-W. (2019). Predictors of performance in everyday technology tasks in older adults with and without mild cognitive impairment. Gerontologist 59, 90-100. doi: 10.1093/geront/gny062

Schwender, C. (2009). "Technische dokumentation für senioren," in Medien und Höheres Lebensalter, eds B. Schorb, A. Hartung, and W. Reißmann (Wiesbaden: VS Verlag für Sozialwissenschaften), 265-274. doi: 10.1007/978-3-531-91900-3_19

Smith, E., Sumner, P., Hedge, C., and Powell, G. (2020). Smart-speaker technology and intellectual disabilities: agency and wellbeing. Disabil. Rehabil. Assist. Technol. 30, 1-11. doi: 10.1080/17483107.2020.1864670
Spriggs, A. D., Mims, P. J., van Dijk, W., and Knight, V. F. (2017). Examination of the evidence base for using visual activity schedules with students with intellectual disability. J. Spec. Educ. 51, 14-26. doi: 10.1177/00224669166 58483

Tsai, W.-C., Rogers, W. A., and Lee, C.-F. (2012). Older adults' motivations, patterns, and improvised strategies of using product manuals. Int. J. Des. 6, 55-65.

Wilkinson, R. (2019). Atypical interaction: conversation analysis and communicative impairments. Res. Lang. Soc. Interact. 52, 281-299. doi: 10.1080/08351813.2019.16 31045

Zimmerman, B. J., and Schunk, D. H (Eds.). (1989). Self-Regulated Learning and Academic Achievement: Theory, Research, and Practice, 1st edn. New York, NY: Springer.

Conflict of Interest: The authors declare that the research was conducted in the absence of any commercial or financial relationships that could be construed as a potential conflict of interest.

Publisher's Note: All claims expressed in this article are solely those of the authors and do not necessarily represent those of their affiliated organizations, or those of the publisher, the editors and the reviewers. Any product that may be evaluated in this article, or claim that may be made by its manufacturer, is not guaranteed or endorsed by the publisher.

Copyright $\odot 2022$ Schlomann, Even and Hammann. This is an open-access article distributed under the terms of the Creative Commons Attribution License (CC BY). The use, distribution or reproduction in other forums is permitted, provided the original author(s) and the copyright owner(s) are credited and that the original publication in this journal is cited, in accordance with accepted academic practice. No use, distribution or reproduction is permitted which does not comply with these terms. 